\title{
SEMIÓTICA E DANÇA NA EDUCAÇÃO INFANTIL: UM RELATO DE EXPERIÊNCIA
}

\section{SEMIOTICS AND DANCE IN EARLY CHILDHOOD EDUCATION: an experience report \\ SEMIÓTICA Y DANZA EN LA EDUCACIÓN DE LA PRIMERA INFANCIA: un relato
de experiência}

Taciane Machado Soares Fernandes Licenciada em Educação Física pela Universidade Federal Rural do Rio de Janeiro (Rio de Janeiro - Brasil). tacisoaresjc@gmail.com

\begin{abstract}
Valéria Nascimento Lebeis Pires Doutoranda em Epidemiologia em Saúde Pública na Escola Nacional de Saúde Pública- Fundação Oswaldo Cruz- FIOCRUZ. Docente da Universidade Federal Rural do Rio de Janeiro (Rio de Janeiro- Brasil). tacisoaresjc@gmail.com
\end{abstract}

Sissi Aparecida Martins Pereira Doutora em Educação Física. Professora do Departamento de Educação Física e Desportos do Instituto de Educação da Universidade Federal Rural do Rio de Janeiro. Coordenadora da Pós-Graduação do Curso Lato Sensu em Pedagogia da Educação Física e do Esporte/UFRRJ. sissimartins@terra.com.br

José Ricardo da Silva Ramos

Doutor em Educação Física.

Professor do Departamento de Educação Física e Desportos do Instituto de Educação da Universidade Federal Rural do Rio de Janeiro. jricardo@ufrrj.com.br

RESUMO: Semiótica é uma proposta que estuda o processo de construção de conhecimento, partindo do pressuposto de que todo conhecimento é produzido por meio de signos, definindo-se este procedimento como processo de semiose. O objetivo deste estudo foi verificar se o conjunto de signos escolhidos facilitou o processo ensino-aprendizagem. Este estudo é de natureza qualitativa, caracterizado como trabalho de campo. Foi desenvolvido na CMEI Hemetério- Seropédica, RJ- com 200 alunos de idades entre três (3) e cinco (5) anos. Baseando-se nos resultados desta pesquisa, pode-se inferir que criar uma linguagem simbólica para as aulas de dança na educação infantil facilitou o processo ensino-aprendizagem e favoreceu a memorização, a consciência corporal, a expressividade, a criatividade e a autonomia.

PALAVRAS-CHAVE: Semiótica. Educação Infantil. Dança. Linguagem simbólica.

ABSTRACT: Semiotics is a proposal that studies the process of knowledge construction, assuming that all knowledge is produced through signs, defining this as semiotic process. The aim of this study was to determine whether the chosen set of signs facilitated the teaching-learning process. This study is qualitative in nature, characterized as fieldwork. It was developed in CMEI Hemetério- Seropédica, RJ with 200 students aged between three (3) and five (5) years. Based on the results of this research, it can be inferred that create a symbolic language for dance classes in early childhood education facilitated the teaching-learning process and favored memorization, body awareness, expressiveness, creativity and autonomy.

KEYWORDS: Semiotics. Early Childhood Education. Dance. Symbolic language.

RESUMEN: La semiótica es una propuesta que estudia el proceso de construcción del conocimiento, en el supuesto de que todo conocimiento se produce a través de signos, que define este proceso como semiótica. El objetivo de este estudio fue determinar si el conjunto de signos elegidos facilitó el proceso de enseñanza-aprendizaje. Este estudio es cualitativo, caracterizado como el trabajo de campo. Fue desarrollado en CMEl Hemetério- Seropédica, RJ con 200 alumnos de edades comprendidas entre los tres (3) y cinco (5) años. Con base en los resultados de esta investigación, se puede inferir que crear un lenguaje simbólico para las clases de danza en la educación de la primera infancia facilitó el proceso de enseñanza-aprendizaje y la memorización favorecida, la conciencia corporal, la expresividad, la creatividad y la autonomía.

PALABRAS CLAVE: Semiótica. Educación de la Primera Infancia. Danza. El lenguaje simbólico.

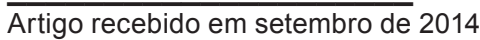

Aprovado em novembro de 2014

Cad. Pes., São Luís, v. 21, n. 3, set./dez. 2014 
SEMIÓTICA E DANÇA | Taciane Machado Soares Fernandes e Valéria Nascimento Lebeis Pires

\section{1 | INTRODUÇÃO}

A dança na educação infantil é apresentada como uma forma de aprender através de experiências corporais desde a infância, cujo movimento é entendido como forma de construção de conhecimento, porque "[...] o corpo que dança e o corpo na dança tornam-se fonte de conhecimento sistematizado e transformador" (MARQUES, 2006, p. 25.).

A semiótica é o estudo de como funciona o pensamento. Esta pesquisa se aprofundará na semiótica proposta por Charles Sanders Peirce, um "lógico, matemático e filósofo norteamericano" (SILVA; SANT' AGOSTINO; BETTI, 2005, p. 30), nasceu em 1839 e foi um grande pensador do século XX. Faleceu em 1914, mas a sua obra só foi reconhecida tardiamente.

Segundo Peirce, todo aprendizado ocorre por meio de signos; e estes são construídos pelo processo de significação que se divide em três categorias fundamentais: primeiridade (uma primeira sensação sem sinal de consciência), secundidade (consciência sem reflexão) e terceiridade (entendimento). O signo é constituído pelo objeto (aquilo que o signo representa), representâmen (o que está representando o objeto) e interpretante (a relação de equivalência entre esses dois) (PEIRCE, 2005).

A semiótica na Educação Infantil associada à dança apresenta uma possibilidade de construir conhecimento desde a infância, a partir das relações do sujeito com ele mesmo, com o outro e com o meio, promovendo o processo de significação dos conteúdos e, portanto, a sensibilização do aluno ao aprendizado.

Com o exposto acima, surgiu uma questão problema: criar uma linguagem simbólica para as aulas de dança na educação infantil facilita a semiose? Facilita o processo ensino-aprendizagem?

O objetivo principal deste estudo foi promover as atividades de dança na educação infantil com a possibilidade de identificar as necessidades emergentes da criança, traçando assim, novos rumos para o processo educativo; rumos esses, baseados nas descobertas, no prazer e na construção de conhecimento, segundo uma perspectiva semiótica.

Este teve como objetivos específicos: construir uma linguagem simbólica para as aulas de dança, direcionada à educação infantil, ou seja, propor atividades dançantes carregadas de significados associando-as à realidade ou vivência corporal do aluno; aplicar esta linguagem como metodologia de aula com objetivo de proporcionar aos alunos a conquista de sua própria autonomia e confiança por meio de experiências corporais significativas, criando, assim, um ambiente de aula favorável à expressividade e à criatividade; e verificar se a linguagem corporal estimulada junto à linguagem verbal simbólica facilita o processo ensino aprendizagem e a memorização dos elementos rítmicos e básicos da dança.

Esta pesquisa justifica-se porque a educação infantil é uma área da educação que carece de mais estudos com objetivos de melhor atender e compreender de forma interdisciplinar e significativa a formação e o desenvolvimento integral da criança. Como também, acredita-se que é importante para alunos, ainda na primeira infância, experimentarem atividades rítmicas e dançantes associadas a uma linguagem simbólica específica para esta faixa etária, pois através dessas experiências eles poderão adquirir consciência do seu corpo, e consequentemente, de si mesmo e de os outros, do meio, assim como, serão incentivados a construir associações em sua vida cotidiana para facilitar o seu processo de aprendizagem. 


\section{2 | REVISÃO DE LITERATURA}

Inicialmente faremos uma exposição mais aprofundada sobre este assunto, abordando os conceitos principais da semiótica e da dança, buscando compreender suas contribuições para a educação infantil.

\subsection{Perspectiva semiótica da educação}

A semiótica é uma proposta de como funciona o pensamento. Para ela, as relações naturais e o processo de produção de conhecimento ocorrem através de relações triádicas (PEIRCE, 2005; SILVA, 2008) que produzem signos. Para a Semiótica, onde houver um ser pensando, dando significado a uma coisa ou internalizando algo, ali há um processo de significação.

Qualquer processo de significação divide-se em três categorias fundamentais: primeiridade, secundidade e terceiridade, estas se denominam relações triádicas (PEIRCE, 2005). A primeiridade está relacionada ao sentimento, a sensação, a qualidade, a liberdade, ao momento sem nenhum sinal de consciência, pois se chegar à consciência é secundidade; e, secundidade é o confronto entre duas forças, é a ideia de dualidade, de dependência, é o surgimento do outro, da ideia de segundo em relação a. Já a terceiridade é "a categoria da inteligência" (MERRELL; QUEIROZ, 2008, p. 288), da generalização, da mediação, da continuidade; "é o domínio do desenvolvimento dos signos [...], da produção das interpretações" (MERRELL; QUEIROZ, 2008, p. 293).

O signo é qualquer coisa que represente outra, seja ela real ou não, pois segundo Peirce (2005, p. 47) '[...] para que algo possa ser um signo, esse algo deve 'representar', como costumamos dizer, alguma coisa [...]" e este é produzido através do processo supracitado. Os autores Silva; Sant'Agostino; Betti (2005) afirmam que, segundo Peirce, a forma mais simples da terceiridade manifesta-se no signo, "[...] o signo é um primeiro (algo que se apresenta à mente), ligando um segundo (aquilo que o signo indica, se refere ou representa) a um terceiro (o efeito que o signo irá provocar em um possível intérprete)" (SILVA, 2008, p. 262).

Mas se já foi exposto como é o processo de significação, então o que constitui um signo? Ele é constituído pelo objeto (é aquilo que o signo representa - seja real ou imaginário), pelo Representâmen (é o que representa o objeto e pode ser um sentimento, um gesto, uma palavra) e o Interpretante (que é o processo de equivalência entre o signo e seu objeto). Essa conexão é denominada de semiose. Então, a semiótica é a ciência que se atém ao estudo da semiose. $\mathrm{E}$, onde houver um processo de significação, de produção de signos ali estarão presentes um objeto, um signo e uma relação de equivalência- interpretante. E, "se há ação do signo, mentes elaborando conteúdos, há aprendizado, há diálogo" (SILVA, 2008, p. 264). Peirce (2005, p. 46) afirma que:

Um signo, ou representâmen, é aquilo que, sob certo aspecto ou modo, representa algo para alguém. Dirigi-se a alguém, isto é, cria na mente da pessoa, um signo equivalente, ou talvez um signo mais desenvolvido. Ao signo criado denomino interpretante do primeiro signo. O signo representa alguma coisa, seu objeto. 


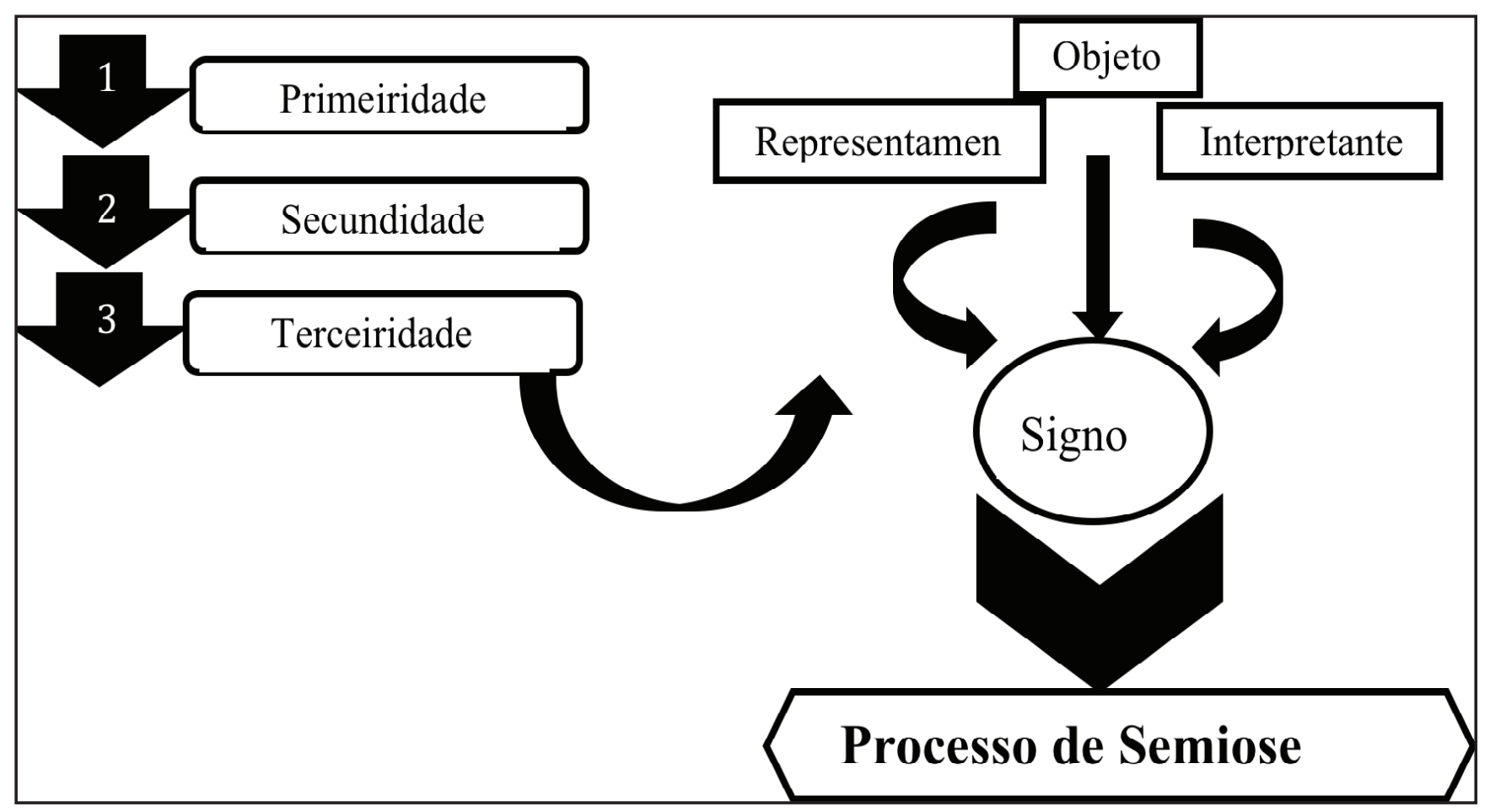

Fonte: Elaborado pelas autoras

O pensamento é signo, e, portanto, o conhecimento é produzido através de signos. Silva; Kunz; Sant'Agostino (2010, p. 32, grifo do autor) citam que:

para Peirce, a produção de conhecimento é sempre uma produção de signos- o pensamento é signo- e o significado de um signo é sempre outro signo, pois o interpretante, ele mesmo é um novo signo, de tal forma que o fluxo de pensamento dá-se em um fluxo incessante de signos, desde que a mente humana trabalha com associações ininterruptas.

Aponta-se que é necessário que os alunos sejam afetados, tenham prazer naquele conteúdo, como também é preciso que os professores sejam comunicativos (SÁNCHEZ; MARTINEZ; PEÑALVER, 2003, p. 15), pois onde há comunicação há aprendizado. Torna-se fundamental que os professores criem um meio propício para que, não apenas os alunos, mas também eles entrem em processo semiótico. Para isso, é essencial que se modifique os parâmetros educacionais, ampliando a noção de processo educativo, libertando os adultos e professores da responsabilidade de serem os detentores do conhecimento, e os únicos responsáveis pelo desenvolvimento da prática pedagógica com a criança; é reconhecer a criança como ser pensante desde o seu nascimento, que produz saberes e não, apenas, como um recipiente de um adulto (SILVA; KUNZ; SANT' AGOSTINO, 2010; MOTTA, 2011).

O professor tem grande responsabilidade na condução do processo comunicativo/cognitivo, porém o aluno também é agente, é sujeito. [...] o professor atua como um signo intermedeia os objetos do mundo ao aluno, ambos produzindo conhecimento nesse processo semiótico. Os três aspectos: mundo, aluno e professor estão envolvidos no processo, em uma trilha de conhecimento (SILVA, 2008, p. 265, grifo do autor). 
É importante também que o conteúdo se misture à sua vivência prévia e cotidiana, não se resumindo, é claro, a apresentar somente a realidade que ele já conhece, mas viabilizar a construção de conhecimentos novos e mais complexos a partir do que o aluno já traz consigo (VERDERI, 2009; RAMOS, 2008).

Esta, então, seria uma perspectiva semiótica da educação, uma proposta baseada na possibilidade de proporcionar ao aluno entrar no processo de semiose, ou seja, construir juntos, professor e aluno, o processo ensino-aprendizagem, pois enquanto um ensina o outro aprende e vice-versa; é o professor estar atento às necessidades e ao contexto de vida do aluno para, desta maneira, apresentar o conteúdo objetivando a sensibilização, pois a partir dela os alunos estarão mais sujeitos ao processo de semiose.

\subsection{Educação Infantil}

A educação infantil é responsável pela escolarização de crianças de zero a seis anos, sendo direto de todos e dever do Estado, segundo a Constituição de 1988, o atendimento a essas crianças; definindo que os municípios devem oferecer prioritariamente o Ensino Fundamental e a Educação Infantil e que à União caberá prestar assistência financeira aos estados, ao Distrito Federal e aos municípios com objetivo de alinhar as oportunidades e de garantir um padrão de qualidade (BRASIL, 1998; BRASIL, 2006; BRASIL, 1990; BRASIL, 1996).

$\mathrm{O}$ avanço maior quanto à regulamentação da educação infantil foi a incorporação desta à educação básica, pois segundo a Lei de Diretrizes e Bases da Educação (LDB) n 9.394, art. 21, inciso I, a "educação básica é formada pela educação infantil, ensino fundamental e ensino médio;" (BRASIL, 1996). No contexto educacional isso muda efetivamente a forma de organização das instituições de educação infantil, porque a partir desse momento a fase da educação infantil começa a ser vista como uma etapa de construção de conhecimento, de aprendizagem, e não simplesmente um lugar onde as crianças passarão o dia enquanto a mãe trabalha, trazendo, desta forma, um cunho pedagógico para essa fase tão importante no desenvolvimento humano.

A educação Infantil caracteriza-se por ser uma fase muito difícil para as crianças, pois, normalmente, pela primeira vez estão sofrendo uma separação do núcleo familiar, com isso, torna-se importante que a Instituição e os educadores sejam acolhedores e "receptivos ao momento maturativo e psicoafetivo da criança" (SÁNCHEZ; MARTINEZ; PEÑALVER, 2003, p. 13). Isto trará um clima de segurança que facilitará o processo semiótico, ou seja, a construção de conhecimento, e ajudará a criança nesta etapa a ser agente ativo na aquisição de conhecimento de si mesma e dos outros, e, assim, poderá alcançar, com prazer, a sua autonomia.

Considerando o momento maturativo e psicoafetivo da criança pode-se afirmar que quanto ao desenvolvimento motor, as crianças de zero a dois anos encontram-se transitando entre os movimentos reflexos e movimentos rudimentares; o primeiro movimento citado refere-se às atitudes corporais involuntárias que as crianças já trazem consigo desde a vida intrauterina, e à medida que o sistema nervoso central (SNC) se desenvolve os movimentos reflexos desaparecem. Já os movimentos rudimentares definem-se como "os primeiros movimentos voluntários e de exploração, como engatinhar, equilibrar-se, segurar etc. e estão presentes no primeiro e no segundo ano de vida" (PEREIRA, 2011, p. 56).

A partir de dois anos de idade as crianças entram na fase dos movimentos fundamentais, chegando ao pleno desenvolvimento desses movimentos aos doze anos. Estes se caracterizam como movimentos voluntários simples, por exemplo, manipulação e locomoção, são eles: correr, saltar, escalar, pendurar-se, rolar, chutar, arremessar (PEREIRA, 2011). 
Sánches; Martinez; Peñalver (2003, p. 71) "o ser humano é eminentemente um ser social e relacionar-se é imprescindível para sua sobrevivência [...]". Logo, é preciso permitir que os alunos, experimentem cada sensação, cada conteúdo, permitir ao aluno descobrir, por meio de suas vivências corporais, as sensações de prazer e bem-estar, para que, assim, possa conhecer a si mesmo, desenvolver e aperfeiçoar suas competências sociais. Silva; Sant'Agostino; Betti (2005, p. 3) dizem que, segundo Peirce "[...] a experiência é o inteiro resultado cognitivo do viver [...]".

Desta maneira, acredita-se que o indivíduo vivencia experiências que produzem conhecimento desde o seu nascimento, pois viver é ter experiências, e experiências produzem signos, e, é necessário dominar a experiência para, então, modificá-la e aprender a lidar com as ansiedades, produzindo conhecimento (SÁNCHEZ; MARTINEZ; PEÑALVER, 2003). Percebe-se, portanto, que a experiência é muito importante para o desenvolvimento da inteligência, pois "a cognição não começa com a representação, mas sim com a interação do organismo com o ambiente" (SILVA, 2008, p. 266, grifo nosso).

As Diretrizes Curriculares Nacionais para a Educação Infantil (2010) apontam como eixos norteadores da proposta curricular a interação e a brincadeira, lembrando a relevância das atividades lúdicas e das relações interpessoais para o aprimoramento do ser humano em todas as suas instâncias. Motta (2011, p. 160) afirma que "O ser humano se constitui na relação com o outro". Portanto, brincar é essencial para a construção cognitiva e psicoafetiva da criança; e o professor na Educação infantil deve preocupar-se em ser mediador de atividades lúdicas com experiências motoras, trabalhando o conteúdo e permitindo o desenvolvimento integral dos seus alunos, a partir da interação social. Segundo Pereira (2011, p. 51) "as experiências motoras vivenciadas pelas crianças no período do nascimento aos seis anos serão decisivas para o futuro adulto".

As crianças possuem uma natureza singular, que as caracteriza como seres que sentem e pensam o mundo de um jeito muito próprio. Nas interações que estabelecem desde cedo com as pessoas que the são próximas e com o meio que as circunda, as crianças revelam seu esforço para compreender o mundo em que vivem, as relações contraditórias que presenciam e, por meio das brincadeiras, explicitam as condições de vida a que estão submetidas e seus anseios e desejos. No processo de construção do conhecimento, as crianças se utilizam das mais diferentes linguagens e exercem a capacidade que possuem de terem ideias e hipóteses originais sobre aquilo que buscam desvendar. Nessa perspectiva as crianças constroem o conhecimento a partir das interações que estabelecem com as outras pessoas e com o meio em que vivem. O conhecimento não se constitui em cópia da realidade, mas sim, fruto de um intenso trabalho de criação, significação e ressignificação (BRASIL, 1998, p. 21-22).

A criança ao entrar na Educação Infantil, já traz consigo um universo lúdico, a linguagem da brincadeira, que muitas vezes se expressa pelo corpo. Então, por que deixar esse universo do lado de fora da escola? Uma prática pedagógica relevante, para a criança, apresenta-se na associação desta ludicidade ao conteúdo de ensino, acarretando em um ambiente de aula motivador e agradável.

Os Parâmetros Curriculares Nacionais (2000) para o Ensino Médio, área de linguagens, códigos e suas tecnologias, apontam que a linguagem não é vazia, ela é a necessidade do ser humano de ser entendido. É a essência da comunicação, e comunicar-se pode ocorrer através de um gesto, um olhar, uma música. A expressão corporal é uma forma de comunicação, considerando expressão corporal linguagem em si mesma, não exclusivamente vinculada às atividades já codificadas culturalmente - dança, jogos, esportes, ou ginásticas (SILVA, SANT' AGOSTINO; BETTI, 2005 , p. 34). Crianças na etapa da educação infantil, na maioria das vezes, utilizam a linguagem da expressão corporal para se comunicar, utilizam o movimento como forma de diálogo. 
Sánches; Martinez; Peñalver (2003, p. 33) afirmam que "O movimento é intrínseco à vida. Fonte em si mesmo de aprendizado permite a aquisição de experiência e estas se convertem, por complexidade, em objetivos e finalidades". O movimento não se caracteriza apenas por uma modificação do corpo no espaço, mas, em primazia, por uma construção mental que reflete os aspectos mais intrínsecos da personalidade e demonstra como o sujeito se situa diante do mundo, sugerindo a existência de uma ligação indissociável entre o plano afetivo-emocional e o cognitivo.

Partindo do pressuposto de que as crianças aprendem pelo corpo, pelas práticas corporais, acredita-se que alunos na etapa da educação infantil aprendam mais facilmente vivenciando as atividades com o seu corpo; Pereira (2011, p. 54) afirma que "a motricidade influenciará diretamente no desenvolvimento da inteligência, na aquisição da linguagem e na organização do pensamento". Logo, se essa motricidade começar ainda na educação infantil, provavelmente esses indivíduos se tornarão mais inteligentes em todas as áreas de sua vida. E, segundo os autores Sánchuez; Martinez; Peñalver (2003, p. 34), "descobrir as sensações de prazer e bem-estar que o próprio corpo proporciona é fundamental para que a criança possa se conhecer e evoluir, desenvolvendo cada vez mais suas competências".

Como parte integrante da expressão corporal, a dança, é uma proposta educacional que deve ser levada em consideração. Pois, durante uma aula de dança os alunos podem libertar-se de excessivas regras que não permitem a expressão da criatividade, podem mergulhar no mundo da fantasia, e o mais importante, experimentar sensações variadas, o que aflora movimentos de dentro para fora, isto é, constrói conhecimento.

\subsection{Dança: uma proposta educativa}

A dança enquanto proposta educativa pode favorecer a formação integral do aluno, pois proporciona a ele o desenvolvimento cognitivo e socioafetivo, assim como favorece o desenvolvimento de sua capacidade crítica e analítica do mundo, favorecendo as relações interpessoais, despertando a expressão intencional, contribuindo para a sensibilidade artística e desenvolvendo o imaginário (BATALHA, 2004). "É por meio de nossos corpos, dançando, que os sentimentos cognitivos se integram aos processos mentais e que podemos compreender o mundo de forma diferenciada [...]" (MARQUES, 2006, p. 25).

Entende-se que a criança que vivencia noções de ritmo, consciência corporal, esquema corporal, coordenação motora, lateralidade, através da dança, por meio de uma proposta lúdica, desde a educação infantil, tem maior probabilidade de se tornar um adulto mais consciente do seu corpo, e, portanto, do corpo dos outros. Formando assim, um indivíduo que exerça a sua cidadania e respeito ao próximo.

Marques (2006) defende que as escolhas de conteúdos na dança podem ser significativas aos alunos quando for levado em consideração o contexto em que estes alunos estão inseridos. Articular as realidades vividas, percebidas e imaginadas pelos alunos pode contribuir para a escolha dos conteúdos, favorecendo um processo de aprendizagem mais libertador e realista, possibilitando uma ação dialógica entre educando e educador no trabalho e na ação-reflexão (FREIRE, 1987).

Segundo Batalha (2004) existem alguns modelos mais difundidos de dança para crianças, que são a Dança Criativa, a Educação Rítmica, a Expressão Dramática e as Rodas e Jogos Cantados. Defende-se que o professor não precisa privilegiar um em detrimento ao outro, mas utilizar determinado modelo para viabilizar a aprendizagem objetivada. 
A Dança Criativa caracteriza-se por uma metodologia própria para o ensino das primeiras destrezas técnicas da Dança na escola. É uma proposta de Ruldolf Laban, um grande pedagogo, que organizou os movimentos fundamentais da técnica da Dança, segundo suas dominantes principais (Corpo, Espaço, Tempo, Dinâmica e Relações), em unidades temáticas, pretendendo desenvolver as bases gerais no campo da expressão gestual (BATALHA, 2004).

Quanto a Educação Rítmica, a autora defende que "a estruturação rítmica favorece a atitude natural da criação e adaptação a diferentes ritmos". Portanto, o sentido rítmico e a capacidade rítmica facilitarão "a intencionalidade da expressão e o domínio dos movimentos" (BATALHA, 2004, p. 231). Fazem parte do conteúdo o ritmo espontâneo, que é o ritmo próprio de cada indivíduo; o ritmo métrico, que são os compassos, as figuras musicais, a acentuação, como também a reconstrução rítmica, caracterizada por improvisação, composição. Ainda sobre ritmo, Verderi (2009, p.61) afirma que: "Toda criança é dotada de ritmo que se manifesta antes mesmo do nascimento, e cabe ao professor aperfeiçoar esse ritmo e adaptá-lo em inúmeras oportunidades".

Estimular e despertar a comunicação através de dramatização, encenação, é o principal objetivo da Expressão Dramática. As relações interpessoais, com o grupo, com o público, são privilegiadas. A proposta é desenvolvida por meio de temas, que são primeiramente escolhidos de acordo com as expectativas dos alunos e depois reorganizados e finalizados para realçar os pontos fortes do discurso. E pretende, com esta intervenção, favorecer a transmissão de mensagens.

E, por fim, as Rodas e Jogos Cantados são caracterizados por colocar em "correlação sensações musicais e respostas motoras e verbais próprias de uma infância". (BATALHA, 2004, p. 232) Essas atividades favorecem a aquisição de habilidades motoras básicas, de noções de ritmo, assim como, favorecem o conhecimento de uma linguagem particular e cultural. E, Ramos (2008, p. 79) afirma que "o papel dos professores, além de ensinar os fundamentos da música, é estimular o potencial criativo de seus alunos para que eles mesmos possam produzir música".

\section{3 | METODOLOGIA}

O presente estudo é de natureza qualitativa (BARDIN, 2011), caracterizado como trabalho de campo com a utilização do método de observação participante. Segundo Minayo (2012, p. 71), a observação participante "ajuda [...] a vincular os fatos a suas representações e a desvendar as contradições entre as normas e regras e as práticas vividas cotidianamente pelo grupo ou instituição observados", o pesquisador está inserido parcialmente no meio observado, pois não há como desvincular-se. A observação participante foi escolhida porque o projeto foi desenvolvido através de aulas práticas, das quais a pesquisadora participava e se dedicou a observar.

Quanto ao procedimento metodológico utilizado para análise dos dados, optou-se por usar o Método de Interpretação de Sentidos, caracterizado como uma perspectiva das correntes compreensivas das ciências sociais, considerando este, o método mais adequado para trabalhar com esta faixa etária. $\mathrm{O}$ método em questão busca conhecer mais afundo a realidade pesquisada, ou seja, objetiva compreender os sentidos das falas e das ações dos indivíduos envolvidos. Os caminhos para a interpretação utilizados no estudo e definidos por Gomes (2012) são divididos em três etapas: a leitura compreensiva do material selecionado, a exploração do material e a elaboração de síntese interpretativa. Na primeira etapa, a pesquisadora buscou a visão de conjunto, como também apreender as peculiaridades do grupo observado. A segunda etapa foi o momento em que a pesquisadora caminhou na direção do explícito para o implícito, do entendido para o subentendido, do que as crianças falavam e se expressavam ao porquê daquela atitude. $E$ a terceira etapa foi o ponto de chegada da interpretação, em que a pesquisadora precisou fazer uma articulação entre os objetivos do estudo, a base teórica adotada e os dados empíricos. 
A primeira etapa, do desenvolvimento do estudo, foi realizada logo no início das aulas, com a observação dos alunos, dos professores, da direção, do ambiente escolar. Durante todo o tempo de trabalho a segunda etapa foi aplicada, pois em todos os momentos houve a preocupação de entender o comportamento exposto pelos alunos, mais especificamente como se colocavam quando um signo-movimento era apresentado. E a terceira etapa, foi a ocasião em que a pesquisador associou todos os dados com as informações teóricas previamente estudadas.

\subsection{Grupo amostral}

O grupo amostral foi constituído por duzentos (200) alunos da Centro Municipal de Educação Infantil (CMEI) Hemetério Fernandes do Rêgo- Seropédica, RJ- com faixa etária entre três e cinco anos, de ambos os sexos e que estavam devidamente matriculados, durante o período entre 2011-2012, cumprindo um ano de projeto.

Os alunos eram divididos conforme a idade de três, quatro e cinco anos. Sendo três turmas de crianças com três anos, duas turmas com idade de quatro anos e três turmas com idade de cinco anos. Todas as turmas tinham em média vinte e oito alunos e cada uma delas tinha duas aulas de trinta minutos em dias alternados, por semana. No primeiro semestre, as aulas ocorreram na sala de brinquedos e no semestre posterior, na quadra de futsal, ambas da Instituição.

Foi desenvolvido um planejamento de aula para cada dia, independente da faixa etária, o que mudava era a intensidade da aula de acordo com a idade dos alunos.

\subsection{O projeto precursor: atividades rítmicas na Educação Infantil}

O projeto precursor foi elaborado pela professora da Universidade Federal Rural do Rio de Janeiro (UFRRJ) Valéria Nascimento e apresentado a esta instituição para a seleção do PROIC. Ele foi aprovado em 2010 e desenvolvido na instituição citada anteriormente. Neste mesmo ano, o projeto foi desenvolvido por duas outras estudantes de Educação Física da UFRRJ e em 2011, com a aprovação novamente do projeto, a pesquisadora pôde participar do seu desenvolvimento e, consequentemente, elaborar esta pesquisa.

A partir de uma inquietação pessoal quanto à facilidade que uma linguagem simbólica pode trazer à aprendizagem, a pesquisadora começou a pesquisar e a estudar a essência desta linguagem, chegando, portanto, ao estudo da semiótica.

Associou o conteúdo de dança a uma linguagem, que acreditava ser mais adequada para alunos dessa idade. Para esta proposta foi designada PALAVRA-SIGNO, o nome simbólico referente ao nome "original", por exemplo: nome original - abdução e adução de quadril alternada e a palavra-signo correspondente - perna de pau. E SIGNO-MOVIMENTO, a palavra-signo acoplada ao movimento estipulado, isto é, a associação completa.

Elaborou um Plano de Curso com os conteúdos propostos associados à linguagem simbólica. Segue abaixo o quadro sobre os conteúdos propostos, distribuídos em tópicos. 


\section{Quadro 1 - Conteúdos propostos durante as intervenções, distribuídos em tópicos}

\begin{tabular}{|c|c|c|}
\hline UNIDADE 1: RITMO & $\begin{array}{c}\text { UNIDADE 2: CONHECIMENTO } \\
\text { CORPORAL }\end{array}$ & $\begin{array}{l}\text { UNIDADE } 3: \text { ELEMENTOS DA } \\
\text { FAMÍLIA DA DANÇA- PARTE } 1\end{array}$ \\
\hline Ritmo espontâneo & O Corpo: & $\begin{array}{l}\text { Planos de movimento - nível alto, médio e } \\
\text { baixo - brincadeira de estátua em níveis }\end{array}$ \\
\hline Ritmo Métrico: Compassos & ${ }^{*}$ Autorretrato & Transferência: \\
\hline $\begin{array}{l}\text { * compasso binário - signo-movimento: } \\
\text { ritmo do coração ou ritmo de "dois" }\end{array}$ & $\begin{array}{l}\text { * Esquema corporal: desenhar o outro no } \\
\text { chão da quadra com giz }\end{array}$ & Transferência no nível alto: \\
\hline $\begin{array}{l}\text { * compasso ternário - signo-movimento: } \\
\text { ritmo de "três" }\end{array}$ & Os Pés: & $\begin{array}{l}\text { * } 2^{\mathrm{a}} \text { posição dos pés en dedans - sig- } \\
\text { no-movimento: o cuco do relógio }\end{array}$ \\
\hline $\begin{array}{l}\text { * compasso quaternário - signo-movimento: } \\
\text { ritmo de "quatro" }\end{array}$ & $\begin{array}{l}\text { * meia-ponta - signo-movimento: andar } \\
\text { como se fosse tocar o céu }\end{array}$ & $\begin{array}{l}\text { * } 4^{a} \text { posição dos pés en dedans - sig- } \\
\text { no-movimento: joão bobo }\end{array}$ \\
\hline $\begin{array}{l}\text { girar em deslocamento - signo-movimento: } \\
\text { giro do pião }\end{array}$ & $\begin{array}{l}\text { * lateral externa do pé - signo-movimento: } \\
\text { andar com a perna torta }\end{array}$ & Transferência no nível baixo: \\
\hline $\begin{array}{l}\text { deslocar-se lateralmente com três passos } \\
\text { e depois uma palma - signo-movimento: } \\
\text { andada com palma }\end{array}$ & $\begin{array}{l}\text { * calcanhar - signo-movimento: os dedos } \\
\text { são uma seta apontada para cima. }\end{array}$ & $\begin{array}{l}\text { * sentado com as pernas flexionadas e as } \\
\text { regiões plantares unidas uma a outra - sig- } \\
\text { no-movimento: canoa }\end{array}$ \\
\hline Aula com arcos & As pernas: & $\begin{array}{l}\text { * sentado com as pernas estendidas- sig- } \\
\text { no-movimento: barquinho }\end{array}$ \\
\hline $\begin{array}{l}\text { colocar arco no chão, o aluno sentado } \\
\text { dentro dele com os pés para fora, deslocar } \\
\text { os pés no compasso }\end{array}$ & $\begin{array}{l}\text { * pernas estendidas - signo-movimento: } \\
\text { perna de pau }\end{array}$ & $\begin{array}{l}\text { * deitado com as pernas estendidas- sig- } \\
\text { no-movimento: balanço }\end{array}$ \\
\hline \multicolumn{3}{|l|}{ quaternário - signo-movimento: reloginho } \\
\hline $\begin{array}{l}\text { o aluno coloca o arco na cintura e tenta } \\
\text { girá-lo o máximo de tempo que conseguir - } \\
\text { signo-movimento: remelexo }\end{array}$ & $\begin{array}{l}\text { * pernas flexionadas - signo-movimento: } \\
\text { perna de gelatina }\end{array}$ & Deslocamento: \\
\hline \multirow{15}{*}{$\begin{array}{l}\text { colocar o arco no pescoço e girar o máximo } \\
\text { de tempo - signo-movimento: pescoço } \\
\text { maluco }\end{array}$} & $\begin{array}{l}\text { * uma das pernas - signo-movimento: perna } \\
\text { de Saci }\end{array}$ & $\begin{array}{l}\text { Conhecimento do espaço-direções: frente, } \\
\text { atrás, lados direito e esquerdo }\end{array}$ \\
\hline & O Tronco: & Deslocamento no nível alto: \\
\hline & $\begin{array}{l}\text { * flexionado para frente - signo-movimento: } \\
\text { como um corcunda }\end{array}$ & $\begin{array}{l}\text { * } 1^{\text {a }} \text { posição dos pés en dehors - signo-mov- } \\
\text { imento: como um pinguim andando }\end{array}$ \\
\hline & $\begin{array}{l}\text { *estendido - signo-movimento: como um } \\
\text { soldado }\end{array}$ & $\begin{array}{l}\text { * } 1^{\text {a }} \text { posição dos pés en dedans - sig- } \\
\text { no-movimento: pé de humano }\end{array}$ \\
\hline & $\begin{array}{l}\text { * flexionado lateralmente - signo-movimen- } \\
\text { to: homenzinho torto }\end{array}$ & $\begin{array}{l}\text { * Um apoio (uma perna) - signo-movimento: } \\
\text { como o Saci }\end{array}$ \\
\hline & $\begin{array}{l}\text { *relaxado juntamente com pernas e braços - } \\
\text { signo-movimento: como uma gelatina }\end{array}$ & $\begin{array}{l}{ }^{*} \text { Saltando com dois apoios (ambas as per- } \\
\text { nas) - signo-movimento: como um coelhinho }\end{array}$ \\
\hline & Os Braços: & \\
\hline & $\begin{array}{l}\text { * flexionados a } 90^{\circ} \text { graus - signo-movimen- } \\
\text { to: braço forte }\end{array}$ & \\
\hline & $\begin{array}{l}\text { * estendido junto ao corpo - signo-movimen- } \\
\text { to: braço de soldado }\end{array}$ & \\
\hline & $\begin{array}{l}\text { * flexão horizontal com os braços estendi- } \\
\text { dos - signo-movimento: braço de múmia }\end{array}$ & \\
\hline & Rosto: & \\
\hline & $\begin{array}{l}\text { * signo-movimento: rosto alegre com sorriso } \\
\text { de palhaço }\end{array}$ & \\
\hline & ${ }^{*}$ signo-movimento: rosto triste & \\
\hline & $\begin{array}{l}\text { * signo-movimento: rosto zangado, chatea- } \\
\text { do }\end{array}$ & \\
\hline & ${ }^{*}$ signo-movimento: rosto de espanto & \\
\hline
\end{tabular}




\subsection{Procedimentos metodológicos}

O projeto de pesquisa foi apresentado ao Comitê de Ética da Universidade Federal Rural/ COMEP-UFRRJ, para aprovação da pesquisa envolvendo seres humanos. O projeto foi aprovado, e tem como número de protocolo: 008507.

Apresentamos uma carta de participação livre e consentida à direção da Instituição CMEI Hemetério Fernandes do Rêgo, na qual ela autoriza a participação dos alunos e a utilização das imagens feitas em aula. Em seguida, as aulas práticas foram iniciadas.

O procedimento foi realizado em três (3) ações investigativas:

a) identificação e associação dos signos, nesta etapa a pesquisadora se dispôs a pensar e a associar o conteúdo da dança às palavras que, segundo ela, faziam parte da realidade prévia dos alunos;

b) relatos espontâneos dos estudantes no momento da introdução do signo. Essa segunda ação investigativa ocorreu durante todo o desenvolvimento da pesquisa, pois em todas as aulas eram apresentados novos signos-movimento e ao mesmo tempo era possível observar o comportamento dos alunos frente à novidade;

c) fotos das atividade aplicadas em aula.

$\mathrm{Na}$ unidade sobre o ritmo, foram utilizados instrumentos de percussão, como tambor pequeno, chocalho e reco-reco, além de arcos e chocalhos de material alternativo, feitos com dois copos descartáveis de $50 \mathrm{ml}$ colados pelas bordas, preenchidos com arroz.

Já na unidade sobre o conhecimento corporal, foi proposto aos alunos desenharem, em uma folha de papel ofício com giz de cera, como eles viam os corpos deles. Em aula seguinte foi pedido que desenhassem com giz, o colega deles (PEREIRA, 2011).

E no conteúdo - conhecimento do rosto - foi utilizada a música "A Linda Rosa Juvenil" (RAMOS, 2008 , p. 80). Ao final desta unidade, foi pedido que os alunos construíssem um corpo, de acordo com o conteúdo ensinado, utilizando massa de modelar.

$\mathrm{Na}$ unidade sobre os elementos da família da dança na parte de deslocamento, a pesquisadora propôs uma brincadeira dançante sobre os planos alto, médio e baixo (CUNHA, 1992). Nesta brincadeira, os alunos dançavam como queriam e quando a música parava, eles "viravam estátua", no momento em que fosse solicitado.

O aparelho de som e as músicas infantis estiveram presentes em todas as aulas, porque os signos-movimento, depois de apresentados aos alunos, eram ordenados de forma rítmica e inseridos nas músicas. Vale ressaltar, que durante as intervenções foram utilizados todos os modelos de dança para crianças, e às vezes, até mais de um por aula, pois, eles estão interligados e se complementam.

E por fim, alguns signos-movimento vivenciados em aula foram utilizados para compor a coreografia que seria apresentada no $3^{\circ}$ Festival de Dança Escolar da Universidade Federal Rural do Rio de Janeiro.

\section{4 | APRESENTAÇÃO E DISCUSSÃO DOS DADOS}

A apresentação dos resultados foi baseada na análise e interpretação da pesquisadora, juntamente com a orientadora, Mestre Valéria Nascimento. Com base nas observações diárias, pode-se perceber que ao propor a união de uma linguagem simbólica ao conteúdo, valorizando a vivência do aluno, facilitou-se a aprendizagem e a memorização do que estava sendo ensinado. A proposta tornou o ambiente de aula agradável, favorecendo a criatividade e a expressividade. Alunos que eram muito tímidos e pouco comunicativos desenvolveram habilidades de socialização du- 
rante o projeto. Confirmando o que Merrell e Queiroz (2008) apontaram sobre a importância de criar uma taxonomia, ou seja, dar nomes, criar uma linguagem mais adequada para a faixa etária, que se trabalha, com objetivo de que os alunos sejam afetados pelo conteúdo.

Um momento relevante para apontar melhora na expressividade foi quando um aluno, que era bastante introvertido e sério, sorriu intensamente, indicando conforto e alegria, no momento que a turma foi conduzida para a aula. Com isso, foi possível observar que o ambiente de aula era agradável e, pôde-se deduzir que se o ambiente é favorável, os alunos sentem liberdade para se expressarem e aprenderem, além de estarem mais sujeitos ao processo de semiose, desenvolvendo autonomia e, assim, tornando-se sujeitos ativos na aquisição de conhecimento.

Ressalta-se, ainda, a importância de o educador ser comunicativo, de ter conhecimento sistematizado da faixa etária com a qual está trabalhando, porque assim poderá proporcionar que os alunos sejam afetados pelo conteúdo, como já defendiam Sánchuez; Martinez; Peñalver (2003).

Outro caso momento marcante foi quando ao passar perto da sala de uma turma, e um dos alunos disse: -“me tira daqui!". Essa exclamação levou à interpretação de que onde o aluno estava não era prazeroso, então como ele entraria no processo de semiose?

Faz-se necessário que as escolas e os educadores revejam seus conceitos quanto às aulas e ao processo ensino-aprendizagem, para compreenderem qual é o melhor veículo para facilitar a aprendizagem; essa compreensão, segundo Marques (2006, 2008), começa quando o educador se disponibiliza a observar o contexto de vida dos seus alunos e a etapa de desenvolvimento motor, afetivo, cognitivo, para escolher e trabalhar os conteúdos de forma que os alunos sejam sensibilizados por eles.

Ao observar o ambiente escolar, foi percebido que as crianças tinham poucas oportunidades de construção de conhecimento por meio do movimento, o que pode ser uma falha, pois "O movimento é intrínseco à vida. Fonte em si mesmo de aprendizado [...]" como afirmam Sánchuez; Martinez; Peñalver (2003, p. 33).

Em outra aula, um aluno perguntou: - "tia, posso contar uma piada!". Essa atitude demonstrou que ele estava autoconfiante e à vontade. Então como forma de retornar ao repouso, foi permitido que os alunos que quisessem, contassem sua piada. Foi interessante para os alunos, pois eles tiveram a oportunidade de se exporem, o que permitiu notar o quanto eles estavam se desenvolvendo e se libertando, e, também, um momento relevante para a avaliação, pela pesquisadora, da expressividade dos alunos. Com tal proposta foi possível perceber que a proposta da dança os ajudou a aprimorarem suas capacidades expressivas e confirmou o que já apontavam Batalha (2004) e Marques (2006).

No decorrer da unidade sobre Ritmo, foi observado que os alunos, de modo geral, não tiveram dificuldades para aprender. Eles ficaram empolgados com as associações propostas, principalmente com a associação do compasso binário, pois ficaram maravilhados em descobrir o ritmo do coração deles e, mais ainda, perceber que o ritmo começa dentro de cada um.

No ensino dos compassos, os alunos experimentaram os ritmos métricos de diversas formas, como por exemplo, andar pela sala de acordo com o compasso que era pedido e fazer o compasso nas partes do corpo.

Também nesta unidade, foram levados instrumentos de percussão e todos tocaram livremente, e com os compassos que tinham aprendido, inventaram músicas. O interessante é que em cada turma surgiram personagens diferentes: maestros, dançarinos de samba, músicos, comprovando que se o ambiente de aula for agradável e se o conteúdo for trabalhado de forma motivadora, os alunos entrarão no processo de semiose, desenvolvendo sua criatividade.

Em outra aula, foram distribuídos arcos entre os alunos para fazerem determinadas posições no ritmo do compasso quaternário. Primeiro, foi pedido que eles colocassem o arco no chão, sen- 
SEMIÓTICA E DANÇA | Taciane Machado Soares Fernandes e Valéria Nascimento Lebeis Pires

tassem dentro com as pernas para fora, e com os pés marcassem o compasso quaternário, girando em volta do arco. Este movimento foi designado de "reloginho". Depois foi pedido que eles colocassem o arco na cintura e que girassem o máximo de tempo possível, este movimento foi chamado de remelexo. Também, que colocassem o arco no pescoço e fizessem o mesmo comando do movimento anterior, este denominado de pescoço maluco. Por último, foi pedido que colocassem o arco de um lado do corpo e que se deslocassem junto com o arco, foi dito que o arco era o cachorrinho deles. Esta proposta teve um feedback agradável, pois foi possível observar que os alunos estavam se divertindo e aprendendo. A associação que eles mais gostaram foi a última citada, o cachorrinho.

Em outra atividade, foram distribuídos arcos entre os alunos e, desta vez, puderam brincar livremente, sem, é claro, machucar os colegas. Neste momento, foi observado que eles criavam personagens ou coisas e compartilhavam com a pesquisadora e com os colegas de turma. Nesta aula surgiram motoristas, peixes, novos jogos. Isto ressalta a importância de planejar a aula com objetivo de proporcionar aos alunos a criação de situações do imaginário e experiências, pois através dessas vivências produzirão conhecimento, desenvolverão as suas capacidades expressivas e a sua criatividade. Como afirmou Peirce (apud SILVA, SANT' AGOSTINO; BETTI, 2005, p. 3) "[...] a experiência é o inteiro resultado cognitivo do viver [...]".

É importante ressalvar também, que uma pessoa faz determinada associação devido a sua experiência e vivência. Isso foi observado e confirmado na aula, sobre compasso quaternário, em que foi proposto o signo-movimento giro do pião pensando no brinquedo popular, no entanto algumas alunas associaram ao peão de boiadeiro, mesmo assim houve a associação, ou seja, a semiose. Entende-se, portanto, que quando o educador propõe um signo, ele não pode mensurar como isso chegará ao aluno, como ele efetuará a associação, mas o importante é propor.

Outro momento considerável, a partir do qual foi avaliada a memorização, foi quando repentinamente e na presença dos alunos, a professora fixa da turma pediu que fosse realizada uma coreografia para os meninos dançarem em um evento. Os próprios alunos sugeriram os signos-movimento que haviam aprendido na aula anterior. Foi significativo perceber que os alunos aprenderam, associaram, memorizaram e foram capazes de pensar e compor uma coreografia.

Mais um episódio importante, ainda na unidade Ritmo, foi quando foi construído um chocalho de material alternativo e distribuído aos alunos; durante as aulas, eles tocavam de acordo com os compassos aprendidos. Este chocalho também foi utilizado na apresentação de Natal, em que foi escolhida uma música característica da data comemorativa, em ritmo de funk, ritmo presente na cultura do bairro no qual a escola está inserida. A proposta da apresentação era que tocassem e dançassem no ritmo da música; e, na coreografia também tinha uma parte na qual os alunos faziam improvisações. Foi observado, que com esta atividade as crianças de três, quatro e cinco anos pensaram seus próprios movimentos.

$\mathrm{Na}$ apresentação da atividade proposta pôde-se observar que as crianças dançaram com muita alegria, sem estarem preocupadas com o erro, demonstrando que aprenderam o conteúdo e que estavam seguras. Os pais também se motivaram e dançaram, revelando, dessa forma a superação das expectativas.

É importante que o educador entenda a apresentação da criança como um momento de diversão do aluno, e não como uma competição entre professores para saber qual a melhor coreografia (MARQUES, 2006). A prova disso, foi o pedido da coordenadora de Educação Física das Instituições Municipais de Educação Infantil de Seropédica para que a música fosse levada a outras Instituições da região.

É importante que o educador entenda a apresentação da criança como um momento de diversão do aluno, e não como uma competição entre professores para saber qual a melhor coreo- 
SEMIÓTICA E DANÇA | Taciane Machado Soares Fernandes e Valéria Nascimento Lebeis Pires

grafia (MARQUES, 2006). A prova disso, foi o pedido da coordenadora de Educação Física das Instituições Municipais de Educação Infantil de Seropédica para que a música fosse levada a outras Instituições da região.

Com esta atividade, tanto as crianças quanto os responsáveis por elas foram sensibilizados ao conteúdo e à apresentação, respectivamente, porque foi respeitado o contexto no qual estas crianças estão inseridas e assim puderam entrar no processo de semiose. Vale ressaltar, também, que com esta proposta, os alunos dançaram funk em um evento natalino, desconstruindo a relação deste estilo de música com a desmoralização e o mau uso da sensualidade. A atividade educativa proposta tornou possível a valorização do contexto de vida dos aluno, além da apresentação de novas perspectivas para o exercício da cidadania e o respeito ao outro.

Inicialmente na unidade sobre o conhecimento corporal, foi proposto que os alunos desenhassem em uma folha de papel ofício como eles se enxergavam, com objetivo de introduzir o conceito global de corpo. A proposta foi válida para observar o nível de desenvolvimento do esquema corporal dos alunos.

Ainda nessa unidade, foi proposto que desenhassem o colega no chão da quadra, utilizando giz para quadro negro. Esta atividade teve o mesmo objetivo da supracitada, mas com uma direção para a socialização dos alunos e a compreensão do corpo do outro. Eles receberam bem a atividade, contudo não conseguiram delimitar exatamente o corpo do colega devido a sua etapa de desenvolvimento cognitivo.

Continuando conhecimento corporal - conhecimento do braço - foi verificado que se a palavra-signo não estivesse no leque de conhecimento e vivência corporal do aluno, esta não tinha efeito, pois não houve associação. Em uma aula, foi empregado o signo-movimento "braço de múmia", que é a elevação frontal dos braços, no entanto, as crianças não sabiam o que era uma múmia, logo não poderiam fazer uma associação com o que não conheciam, isto confirma o que já tinha sido exposto no referencial teórico por Silva (2008), quanto a necessidade de o conteúdo estar associado à realidade do aprendente.

Em função dessa não associação, foi proposta outra nova palavra-signo para se acoplar àquele movimento - "dedinhos que cumprimentam", cuja diferença do movimento anterior, é que os alunos se cumprimentariam tocando os dedos. Esta palavra-signo alcançou o objetivo da associação, ou seja, os alunos entenderam a proposta e realizaram a associação satisfatoriamente.

Ainda nesta unidade - o conhecimento do rosto - houve a designação dos tipos de expressão já codificados culturalmente (alegre, triste, zangado e espanto). Estes foram colocados nos compassos, proporcionando aos alunos dançarem com o rosto. A atividade permitiu a observação de quanto os alunos gostaram e se divertiram com a proposta.

Prosseguindo o conhecimento do rosto, outra proposta que teve resultado satisfatório foi a encenação da música, "A Linda Rosa juvenil". Nesta aula foi levado um figurino para todos os alunos e dito a eles que a cada fase da história deveriam usar as expressões expostas na aula anterior, como por exemplo, apareceu a bruxa, rosto de espanto, e assim por diante. Além de dançarem, os alunos se expressaram muito bem, como se fossem atores, utilizando os métodos de Dança, Rodas e Jogos Cantados, Expressão Dramática e Dança Criativa (BATALHA, 2004).

Ao final da unidade, foi pedido que os alunos fizessem um corpo, compondo-o com as partes que tinham sido ensinadas, utilizando massa de modelar. Essa atividade serviu também como forma de avaliação do que foi ensinado. Foi observado, que, não apenas esta proposta, como todo o trabalho desenvolvido, favoreceram a construção do esquema corporal dos alunos, o corpo construído por eles estava praticamente com todos os detalhes, confirmando a importância de proporcionar esta vivência ainda na educação infantil, como já defendia Marques $(2006,2008)$. 
Na unidade sobre os elementos da família da dança, foi proposta a brincadeira de estátua nos planos de movimento. A proposta foi aplicável, pois os alunos aprenderam brincando e desenvolveram a criatividade ao pensar que poses fariam.

Ao final do período de intervenção, construímos uma coreografia com os movimentos aprendidos através dos signos-movimento. Os alunos já haviam memorizado e só foi necessário pronunciar a palavra-signo, pois eles já sabiam o movimento correspondente, o que demonstra que a associação foi completa e houve construção de conhecimento. O objetivo da coreografia era apresentá-la no $3^{\circ}$ Festival de Dança Escolar da UFRRJ, no entanto, por falta de verba para o figurino não foi possível.

\section{5 | CONSIDERAÇÕES FINAIS}

Com base nos relatos supracitados, pode-se inferir que criar uma linguagem simbólica para as aulas de dança na educação infantil facilitou o processo ensino-aprendizagem e favoreceu a expressão corporal e afetiva da criança. Assim como, as atividades rítmicas e dançantes associadas à Semiótica favoreceram a memorização, a consciência corporal, a expressividade, a criatividade e a autonomia dos alunos.

Quanto ao desenvolvimento da dança na educação infantil, pôde-se perceber que esta proposta foi bem recebida pelos alunos, que participaram e se divertiram durante as intervenções. E quanto aos modelos de dança para crianças (Dança Criativa, Educação Rítmica, Expressão Dramática e rodas e Jogos Cantados), a seleção feita por Batalha (2004) foi aplicável e cada modelo foi utilizado para atender a um objetivo de aula. Todos os movimentos foram trabalhados ritmicamente.

Em uma análise geral sobre a linguagem simbólica, pôde-se observar que quando um signo-movimento era introduzido à aula havia uma excitação dos alunos, ou eles inventavam outro signo para aquele movimento, ou faziam o movimento com alegria, ou ficavam comentando uns com os outros sobre aquilo. Às vezes, tudo isso ao mesmo tempo.

Então, é com esta função facilitadora que a semiótica adentra as aulas, proporcionando uma melhor comunicação professor-aluno e possibilitando a sensibilização do aluno ao conteúdo proposto, partindo do princípio de que todo aprendizado se dá através de signos.

Este estudo apresenta uma possibilidade de construir conhecimento desde a infância, a partir das relações do sujeito com ele mesmo, com o outro e com o meio, promovendo o processo de significação dos conteúdos por meio da linguagem simbólica. 


\section{Referências}

BATALHA, A. P. Metodologia do ensino da dança. Cruz Quebrada: Faculdade de Motricidade Humana; Serviço de Edições, 2004.

BARDIN, L. Análise de Conteúdo. São Paulo: Edições 70, 2011.

BRASIL. Lei $n^{\circ}$ 8.069, de 13 de julho de 1990. Dispõe sobre o Estatuto da Criança e do Adolescente e dá outras providências. Diário Oficial da União. Brasília, DF, 16 jul. 1990.

Lei $n^{\circ}$ 9.394, de 20 de dezembro de 1996.

Estabelece as Diretrizes e Bases da Educação Nacional. Diário Oficial da União. Brasília, DF, 23 dez. 1996.

. Ministério da Educação. Secretaria de Educação Básica. Diretrizes Curriculares Nacionais para a Educação Infantil. Brasília, DF: MEC; SEB, 2010.

Ministério da Educação. Secretaria de Educação Básica. Parâmetros Curriculares Nacionais para o Ensino Médio. Brasília, DF: MEC; SEB, 2000.

. Ministério da Educação. Secretaria de Educação Básica. Política Nacional de Educação Infantil: pelo direito das crianças de zero a seis anos à educação. Brasília, DF: MEC; SEB, 2006.

Ministério da Educação e do Desporto.

Secretaria de Educação Fundamental. Referencial curricular nacional para educação infantil. Brasília, DF: MEC;SEF, 1998. 3v.: il.

CUNHA, M. Dance aprendendo- aprenda dançando. 2. ed. Porto Alegre: Sagra- DC Lozano, 1992.

FREIRE, P. Pedagogia do Oprimido. 17. ed. Rio de Janeiro: Editora Paz e Terra S/A, 1987.

GOMES, R. Análise e interpretação de dados de pesquisa qualitativa. In: MINAYO, M. C. de S. (Org.). Pesquisa social: teoria, método e criatividade. 31. ed. Petrópolis, RJ: Vozes, 2012. p. 79-108.

MARQUES, I. A. Dançando na escola. 3. ed. São Paulo: Cortez, 2006, p. 13-33,

Ensino de dança hoje: textos e contextos. 5. ed. São Paulo: Cortez, 2008.

MERRELL, F.; QUEIROZ, J. Borges e as categorias lógico-fenomenológicas de Peirce. ALEA, v. 10, n. 2, p. 288-303, jul./dez. 2008.
MINAYO, M. C. de S. Trabalho de campo: contextos de observação, interação e descoberta. In: MINAYO, M. C. de S. (Org.). Pesquisa social: teoria, método e criatividade. 31. ed. Petrópolis, RJ: Vozes, 2012. p. 61-78.

MOTTA, F. M. N. De crianças a alunos: transformações sociais na passagem da educação infantil para o ensino fundamental. Educação e Pesquisa, v.37, n.1, 220p. 157-173, jan./abr. 2011.

NASCIMENTO, V. Dança em educação: considerações sócio-pedagógicas. In: VARGAS, A. (Org.). Questões do esporte: coletivo de autores. Rio de Janeiro: LECSU, 2008.

PEIRCE, C. S. Semiótica. Tradução José Teixeira CoeIho Neto. São Paulo: Perspectiva, 2005.

PEREIRA, S. A. M. O movimento na infância: conhecer para intervir. In: PEREIRA, S. A. M.; SOUZA, G. M. C. (Org.). Educação física escolar: elementos para pensar a prática educacional. São Paulo: Phorte, 2011.

RAMOS, J. R. da S. Dinâmicas, brincadeiras e jogos educativos: brincadeiras cantadas (inclui CD), brinquedos com sucata, jogos do cotidiano escolar, dinâmicas de alta e baixa intensidade motriz, jogos historiados. Ilustrações de Ricardo Goulart. 3. ed. Rio de Janeiro: Lamparina, 2008.

SÁNCHEZ, P. A.; MARTÍNEZ, M. R.; PEÑALVER, I. V. A psicomotricidade na educação infantil: uma prática preventiva e educativa. Tradução de Inajara Haubert Rodrigues. Porto Alegre: Artmed, 2003.

SILVA, A. C. T. da. A Perspectiva semiótica da educação. Revista Teoria e Prática da Educação, v. 11, n. 3, p. 259-267, set./dez. 2008.

SILVA, E. G.; KUNZ, E.; SANT'AGOSTINO, L. H. F. Educação (física) infantil: territórios de relações comunicativas. Revista Brasileira de Ciência e Esporte, v. 32, n. 2-4, p. 29-42, dez. 2010.

SILVA, E. G.; SANT'AGOSTINO, L. H. F.; BETTI, M. Expressão corporal e linguagem na educação física: uma perspectiva semiótica. Revista Mackenzie de Educação Física e Esporte, ano 4, n. 4, p. 29-38, 2005.

TAUBE, M. L. Estudo qualitativo do desenvolvimento da capacidade rítmica da criança. Revista Movimento, ano 5, n. 9, p. 3-16, 1998/2.

VERDERI, É. Dança na escola: uma abordagem pedagógica. São Paulo: Phorte, 2009. 